\title{
Ventilatory responses to skin extract in catfish
}

\author{
Rodrigo Egydio Barreto ${ }^{1, *}$, Augusto Barbosa Júnior ${ }^{2}$, Anette Hoffmann ${ }^{2}$ \\ ${ }^{1}$ Departamento de Fisiologia, Instituto de Biociências, Caunesp, UNESP, Rubião Jr. s/n, Botucatu, São Paulo 18618-970, Brazil \\ ${ }^{2}$ Laboratório de Neurofisiologia Comparada, Departamento de Fisiologia, Faculdade de Medicina de Ribeirão Preto, USP, \\ Av. Bandeirantes 3900, Monte Alegre, Ribeirão Preto, São Paulo 14049-900, Brazil
}

\begin{abstract}
The ventilation rate (VR) of an ostariophysan fish, the speckled catfish Pseudoplatystoma coruscans, exposed to a chemical alarm cue was measured in the present study in multiple contexts. The influence of the extraction techniques, skin donor food intake and quantity of the alarm cue (skin extract) on this autonomic response was considered. Overall, the catfish VR decreased significantly when exposed to the skin extract (chemical alarm cue) compared with exposure to distilled water (control). No effect of the extraction technique was found. Increasing doses of the skin extract induced a VR reduction of similar magnitude. However, extract obtained from daily-fed fish induced a significant decrease in the VR, whereas extract obtained from foodrestricted fish did not induce any change in the VR. Thus, food intake was associated with the production of a more easily recognizable alarm cue in the speckled catfish. Interestingly, this effect was not related to differences in the number of club cells in the donor catfish epidermis. Dashing, or rapid swimming, a normal component of the alarm response in fish, including this catfish species, was not observed here, and hypoventilation was always associated with no swimming reaction. Together, these results suggest that hypoventilation is a reaction to a chemical alarm cue, likely resulting in improved crypsis, causing the fish to become less easily perceived by a potential predator that usually strikes prey in response to movement.
\end{abstract}

KEY WORDS: Stress - Antipredator behavior - Chemical communication - Alarm substance · Neurovegetative system $\cdot$ Opercular beat rate

\section{INTRODUCTION}

Environmental chemical alarm cues mediate antipredator responses in fish. These cues have been particularly well studied in species from the Superorder Ostariophysi, which have club cells in their epidermis that are hypothesised to produce and store putative chemical alarm cues (Pfeiffer 1977, Smith 1992, Chivers \& Smith 1998). These cues are released in the water by the mechanical damage of the skin during the capture stage of a predation event. This event promptly alerts the conspecifics, which display alarm reactions that involve behavioural and physiological changes (von Frisch 1941, Pfeiffer 1977, Chivers \& Smith 1998, Wisenden 2000). The behavioural responses to chemical alarm cues are rela- tively well documented. Species-typical characteristics generally involve flight (dashing), freezing, shoaling, sheltering and crypsis (Chivers \& Smith 1998, Smith 1999, Brown 2003). The autonomic correlates of these responses, however, are less studied.

The early detection of a predator has an important role in defence as the animal may prepare its body for performing anti-predator responses. Defence, like other stressful situations, increases alertness, and ventilatory adjustments are expected. A function of the ventilatory system is to supply the body with enough oxygen for all behavioural tasks, including escape responses. Increasing the ventilatory rate (VR) is a common ventilatory adjustment to repay oxygen debt (Fernandes \& Rantin 1994) that is often used in stressful situations (Volpato et al. 1989, Alva- 
renga \& Volpato 1995, Sager et al. 2000, Barreto \& Volpato 2004, 2006, Brown et al. 2005, Ernst et al. 2007, Bell et al. 2010), including predation risk (von Frisch 1941, Metcalfe et al. 1987, Barreto et al. 2003, 2010, Hawkins et al. 2004a,b, 2007, Queiroz \& Magurran 2005, Gibson \& Mathis 2006). However, increased movements of the gills could make fish more visible to potential predators because many predators rely on movement stimuli to track prey (Burrows et al. 1994, Burrows \& Gibson 1995). Alternatively, responding to a predation threat by reducing the VR would increase crypsis, particularly if the prey concomitantly adopts a fixed or immobile posture to become less susceptible to detection by predators. Moreover, if crypsis fails, a decreased VR would not impair an emergency escape manoeuvre. An escape can be performed anaerobically, requiring no elevation of the VR, especially because an increased VR is itself a high-energy cost reaction (Hughes \& Shelton 1962, Millidine et al. 2008), and reducing the VR decreases the organism's energy requirement (Hanlon et al. 1999, Losey 2003). As previously reported, fish can exhibit bradycardia (Holopainen et al. 1997, Johnsson et al. 2001, Shingles et al. 2005) or reversible cardiac arrest (Ide \& Hoffmann 2002) in response to adverse stimuli, including predator threats.

The speckled catfish Pseudoplatystoma coruscans is a South American ostariophysan whose alarm reaction to chemical cues from injured conspecifics (skin extract) has been previously reported (Giaquinto \& Volpato 2001, Giaquinto \& Hoffmann 2010). These authors showed that this response has 2 components: dashing followed by immobility, or immobility alone. Because this fish species responds to skin extract, it is a suitable animal model to assess how the VR is affected by a chemical alarm cue. We hypothesise that dashing increases the VR to support escape tasks, and alternatively, immobility decreases the VR. To test these hypotheses, we predicted that in speckled catfish, the VR would increase (dashing fish) or decrease (immobile fish) more in response to the skin extract than to distilled water (cue diluent; control). Additionally, 2 different techniques for chemical cue extraction, the effect of food intake of the conspecific skin donor and the extract volume provided to the fish studied were considered. We measured the VR by counting the frequency of opercular or buccal movements, which is a convenient technique and a reliable measure of the fish alarm reaction (Barreto et al. 2003, 2010, Hawkins et al. 2004a,b, 2007, Queiroz \& Magurran 2005, Gibson \& Mathis 2006, Bell et al. 2010.

\section{MATERIALS AND METHODS}

Animal welfare statement. This study complies with the Ethical Principles in Animal Research adopted by the Brazilian College of Animal Experimentation (COBEA) and was approved by the School of Medicine of Ribeirão Preto of the University of São Paulo, Ethics Committee in Animal Research (CETEA), Protocol no. 010/2006.

Fish and holding conditions. Hatchery-raised catfish Pseudoplatystoma coruscans (Spix \& Agassiz, 1829) (Pimelodidae) were used as our stock population. For all experiments, the donor and test fish came from this stock. Before the tests, juvenile fish (standard length $\sim 11 \mathrm{~cm}$; body weight $\sim 10$ to $11 \mathrm{~g}$; sexually immature; mixed sex) were held at least 1 mo in indoor 2701 tanks containing dechlorinated tap water (water volume $\sim 235 \mathrm{l}$; $\sim 1$ fish per 4.7 l; holding density $\sim 5 \mathrm{~g} \mathrm{l}^{-1}$ ). Each stock tank was fitted with a mesh cover to prevent fish from jumping and partially covered $(50 \%)$ with an opaque partition to increase shadowing. The fish were kept under a natural photoperiod and illumination. The water temperature was maintained at $\sim 27^{\circ} \mathrm{C}$ with continuous aeration and systemic recirculation through a biological-chemical-mechanical filter. At least 201 of dechlorinated water was changed twice a week. The fish were fed ( $\sim \%$ fish weight) earthworms every $2 \mathrm{~d}$ ( $20 \mathrm{~g}$ in each feeding).

General experimental design. The fish VR was studied in response to conspecific skin extracts. The basic design (based on Wisenden et al. 2008) consisted of evaluating the effects on the ventilation rate of exposing speckled catfish to skin extract (chemical alarm cue) or distilled water (cue extract vehicle) ( $\mathrm{n}=6$ to 7 for each experimental condition). For this, fish were randomly chosen and individually housed (1 fish per tank) for acclimating in glass tanks $(29.5 \times 25 \times 14 \mathrm{~cm})$ for 10 consecutive days. Basal VR values were then measured by counting the VR 5 times (every 2 min during a 10 min period $=5$ observations). Immediately after the basal measurements, the eluate or distilled water was added with a syringe to the water surface of the test-fish aquarium (as in Gibson and Mathis 2006). A dye test with methylene blue showed that the colorant was completely spread throughout the aquarium in $<8$ s. The VR was immediately recorded every 2 min after addition up to the 10th minute (totalling 5 observations). The VR $\left(\mathrm{min}^{-1}\right)$ was calculated by measuring the time needed for 20 successive opercular or buccal movements to occur (adapted from Alvarenga \& Volpato 1995). 
Experimental eluate preparation. For eluate preparation, donor fish were killed by a blow to the head. Then we used 2 techniques. (1) For the skin homogenate preparation, skins were collected from both sides of the body, immediately rinsed with abundant distilled water and placed into $100 \mathrm{ml}$ of chilled distilled water (extract eluent). To collect the skin, shallow cuts, marking a trapezoidal area, were made on each side of the trunk of all donor fish, and the skin was carefully removed without muscle fragments or visible blood, ensuring that nothing contaminated the solution. The skin samples were homogenised and filtered through $185 \mathrm{~mm}$ filter paper (Whatman 40) to remove tissue debris. The filtered homogenates were frozen $\left(-20^{\circ} \mathrm{C}\right)$ in $1 \mathrm{ml}$ aliquots in capped tubes until required for experimentation. Distilled water aliquots were used as controls. These procedures were based on Brown et al. $(2004,2006)$ and Foam et al. (2005).

(2) For cut skin extract preparation, dead donor fish skin immediately received 20 shallow cuts with a sterile surgical scalpel along the body. The fish was then placed into a beaker with $20 \mathrm{ml}$ of chilled distilled water (eluent) and gently swirled for $5 \mathrm{~min}$. The liquid obtained was filtered through $185 \mathrm{~mm}$ filter paper (Whatman 40) and immediately applied to the test fish tank by drawing it into a $20 \mathrm{ml}$ syringe. Distilled water was used as a control stimulus. These procedures were based on Valentincic \& Caprio (1994) and Giaquinto \& Volpato (2001).

Expt 1: skin homogenate and cut skin extract. We evaluated the VR in response to the extract obtained from homogenised or cut skin and compared to distilled water (control). The VR of fish exposed to the extract from cut skin was also compared to those exposed to that of skin homogenate to assess any specific technique effect. To quantify VR, we followed the protocol described by Gibson \& Mathis (2006) who quantified the VR by direct visual examination of opercular movement, i.e. the experimenter is visible to the fish. To evaluate the effect of investigator presence, we inspected fish locomotion by video recording the fish activity, and locomotion was quantified from these records. During the acclimation days (see 'General experimental design'), a camera sustained by a tripod was assembled a few times in front of the test tanks for habituation.

Speckled catfish antipredator behaviour has 2 motor components: dashing and freezing (Giaquinto \& Volpato 2001). Dashing is a fast episode ( 5 to $30 \mathrm{~s})$ of high-speed swimming in unpredictable trajectories. Freezing consists of an abrupt cessation of swimming (the dashing) and staying in this motionless state for up to $6 \mathrm{~h}$. In the present study, locomotion was estimated by attaching a grid of 9 equal quadrants on the rear wall of each tank and quantifying the frequency of quadrant changes of the fish (adapted from Jordão \& Volpato 2000 and Barreto et al. 2010).

Expt 2: effects of skin-donor food intake. We counted the VR in response to the chemical alarm cue obtained from the homogenised skin of full-fed or starved donors because the quality of the alarm cue is purported to be related to the feeding state of the fish (Brown et al. 2004).

For the preparation of the extract, 11 donor catfish were allocated to 2 different feeding condition groups: feed-restricted $(n=5)$ or full-fed $(n=6)$. These 2 feeding conditions were imposed for $20 \mathrm{~d}$. Each group of fish was housed in water-filled glass tanks $(39.5 \times 26$ $\times 22 \mathrm{~cm}$ ) that were lined with gravel substrate, under constant aeration and fitted with a biological filter. Full-fed donors were fed daily with $2 \mathrm{~g}$ of earthworms per fish, whereas feed-restricted donors were fed the same amount every $2 \mathrm{~d}$. This amount of food allowed all of the fish to eat, and the leftover food was removed 30 min later. At the onset and after the $20 \mathrm{~d}$ period of different feeding regimes, each fish was measured in terms of mass and length. In addition, the Fulton's condition factor of the body ( $\mathrm{K}=$ mass/length ${ }^{3}$ ) was calculated for each fish (Froese 2006). Mass, length and condition factor differences between fish under the different feeding conditions were compared using an unpaired Student's $t$-test for both the initial and final measurements because the data were considered normally distributed and homoscedastic. At the onset of the feeding regimes, there was no difference between the full-fed and feed-restricted conditions mean $( \pm \mathrm{SD}$ ) mass (full-fed $=10.2 \pm 0.8 \mathrm{~g}$, feed-restricted $=10.0 \pm 0.7 \mathrm{~g} ; t=0.17$; $\mathrm{p}=0.872$ ), length (full-fed $=10.2 \pm 0.9 \mathrm{~cm}$, feedrestricted $=10.4 \pm 0.6 \mathrm{~cm}_{i} t=0.35 ; \mathrm{p}=0.735$ ) or condition factor (full-fed $=0.96 \pm 0.12 \mathrm{~g} \mathrm{~cm}^{-3}$, feedrestricted $=0.91 \pm 0.09 \mathrm{~g} \mathrm{~cm}^{-3} ; t=0.59 ; \mathrm{p}=0.282$ ). After $20 \mathrm{~d}$ of the feeding regimes, however, the fullfed fish were heavier (full-fed $=13.5 \pm 0.6 \mathrm{~g}$, feedrestricted $=11.0 \pm 0.7 \mathrm{~g} ; t=2.96 ; \mathrm{p}=0.016$ ) and longer (full-fed $=12.8 \pm 0.5 \mathrm{~cm}$, feed-restricted $=11.5 \pm 0.6 \mathrm{~cm} ; t=2.49 ; \mathrm{p}=0.035$ but not heavier for a given cubic length (full-fed $=0.85 \pm 0.04 \mathrm{~g} \mathrm{~cm}^{-3}$, feed-restricted $=0.85 \pm 0.05 \mathrm{~g} \mathrm{~cm}^{-3}$; condition factor; $t=0.87 ; \mathrm{p}=0.466$ ) than those subjected to feed restriction. These procedures were based on Brown et al. (2004).

In addition, the skin was analysed histologically to assess the presence and number of club cells as well as the epidermis thickness in feed-restricted and 
full-fed fish. A piece of the epidermis attached to the underlying musculature was removed from killed fish and preserved in 10\% formaldehyde. Tissue samples were embedded in paraffin, sectioned (6 $\mu \mathrm{m}$ thick), stained using Schiff's reagent and counterstained with haematoxylin (PAS-H) (Wisenden \& Smith 1997, 1998, Kristensen \& Closs 2004). Stained sections were examined under a light microscope, the occurrence of club cells was checked, and the number of these cells was scored in an area of skin $0.10 \mathrm{~mm}$ wide in 6 epidermal sections for each fish. A single average score of the number of club cells was calculated for each fish. Three measures of the epidermal thickness (surface to basement lamina) for each epidermal section of each fish were taken and averaged for statistical analysis. These procedures were based on Wisenden \& Smith $(1997,1998)$.

Expt 3: effect of extract concentration. We observed the VR in response to increasing volumes of homogenised skin extract of full-fed donor fish from Expt 2. Fish in each group were exposed to $0.1 \mathrm{ml}$, $1.0 \mathrm{ml}$ or $15 \mathrm{ml}$ of skin extract or to a distilled water control. The volumes $(0.1,1.0$ and $15.0 \mathrm{ml})$ were based on Ide et al. (2003) (matrinxã Brycon cephalus), Brown et al. (2004) (convict cichlid Archocentrus nigrofasciatus), the present study (previous trials) and Barreto et al. (2010) (Nile tilapia Oreochromis niloticus). Distilled water was added to the $0.1 \mathrm{ml}$ and $1.0 \mathrm{ml}$ extracts to reach $15 \mathrm{ml}$ total volume which was added to each tank.

Physico-chemical condition. Each tank was lined with $\sim 350 \mathrm{~g}$ of neutral gravel, and provided with constant aeration. Throughout all of the trials, the mean water temperature was $\sim 27^{\circ} \mathrm{C}$, the $\mathrm{pH}$ ranged from 6.6 to 7.2 , and the nitrite and ammonia concentrations were both $<0.05 \mathrm{mg} \mathrm{l}^{-1}$. Illumination (from a daylight fluorescent lamp) was maintained in a 12:12 $\mathrm{h}$ light:dark cycle, with an abrupt light:dark transition (lights on at 06:00 h and off at 18:00 h) controlled by a timer.

Statistical analyses. The 5 baseline VR values and 5 post-stimulation VR values were averaged for analysis, resulting in 1 mean baseline VR and 1 mean post-stimulation VR value. The VR values were studied using the difference between post- and prestimulation (baseline) VR values for each animal. This allowed us to adjust the post-stimulus VR level according to the baseline measurement of each fish; thus, each fish also acted as its own control. Data normality and homoscedasticity were analysed using Kolmogorov-Smirnov and Bartlett tests or F-max, respectively. Parametric or non-parametric analyses were used as necessary. Baseline VRs were normally distributed and homoscedastic. To ensure that the fish started from similar baseline VRs, they were compared by unpaired Student's $t$-test or 1-way ANOVA. Changes in VR were considered normally distributed but were heteroscedastic even after square-root transformation. Thus, the VRs were compared using the Mann-Whitney $U$-test in Expt 1 and by a Kruskal-Wallis ANOVA followed by a StudentNewman-Keuls test of rank values in Expts 2 and 3. No analysis of locomotion data was necessary because the fish remained motionless in response to stimuli (Expt 1). The values of epidermis thickness and club cell scores (Expt 2) obtained for full-fed and feed-restricted donors (values normally distributed and homoscedastic) were compared using an unpaired Student $t$-test, and in both cases, the correlation between the epidermis thickness and club cell score was evaluated with Pearson's correlation test. The differences were considered significant when $\mathrm{p}<0.05$.

\section{RESULTS}

Baseline of ventilation rate. Before the extract addition, the mean VR was statistically indistinguishable among the fish within each experiment, confirming that the fish started from a similar baseline stress state (Table 1).

Expt 1: skin homogenate and cut skin extract. After the addition of the extract to the test tank, the VR was lower in the fish exposed to the extract than in the control fish (Fig. 1) (Mann-Whitney U-test; extract from homogenised fish skin, $\mathrm{p}=0.048$; extract from cut skin, $\mathrm{p}=0.025)$. The hypoventilations observed in the fish exposed to the extract were similar in magnitude, ruling out the influence of the extraction technique on the response (Mann-Whitney $U$-test; $\mathrm{p}=0.50$ ). Based on the video recordings of fish locomotion to eliminate the effect of investigator presence, the fish were motionless during the 10 min preceding the addition of the extract or distilled water, and no detectable motor change was observed after the addition; similar behaviour was noted in all trials.

Expt 2: effects of skin-donor food intake. Histological analysis revealed the presence of club cells in the epidermis of all of the donor specimens examined (Fig. 2). The differences in club cell number between full-fed (mean $\pm \mathrm{SD}=6.9 \pm 0.7$ ) and feed-restricted $(7.0 \pm 1.3)$ skin donors (unpaired Student's $t$-test, $t=$ $0.15 ; \mathrm{p}=0.88, \mathrm{n}=6-5$ ) and the epidermis thickness $(\mu \mathrm{m})$ between full-fed $(29.7 \pm 5.1)$ and feed-restricted $(29.6 \pm 4.9)$ skin donors (unpaired Student's $t$-test, $\mathrm{p}=$ 
Table 1. Pseudoplatystoma coruscans. Ventlation rates (mean $\pm \mathrm{SD}_{\text {; }}$ beats $\mathrm{min}^{-1}$ ) in the speckled catfish from all experiments. Rates were compared using an unpaired Student's t-test (2 conditions) or 1-way ANOVA (3 to 4 conditions). Significant differences were considered when $\mathrm{p}<0.05$. SH: skin homogenate $(\mathrm{n})$ : sample size $;$-: no data

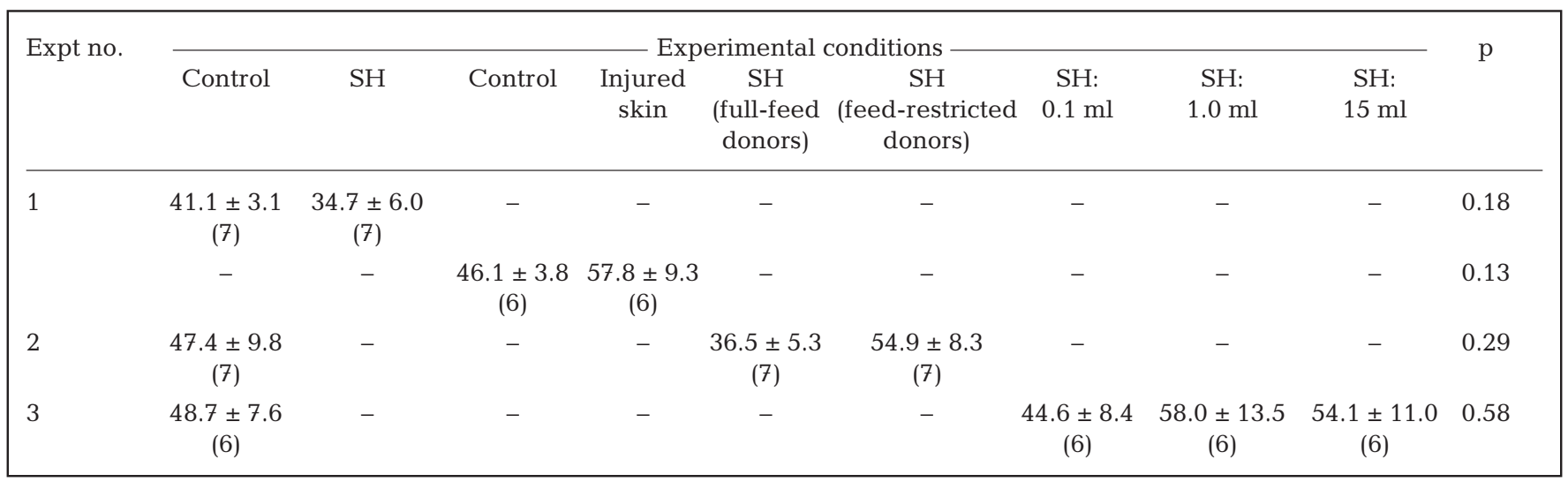
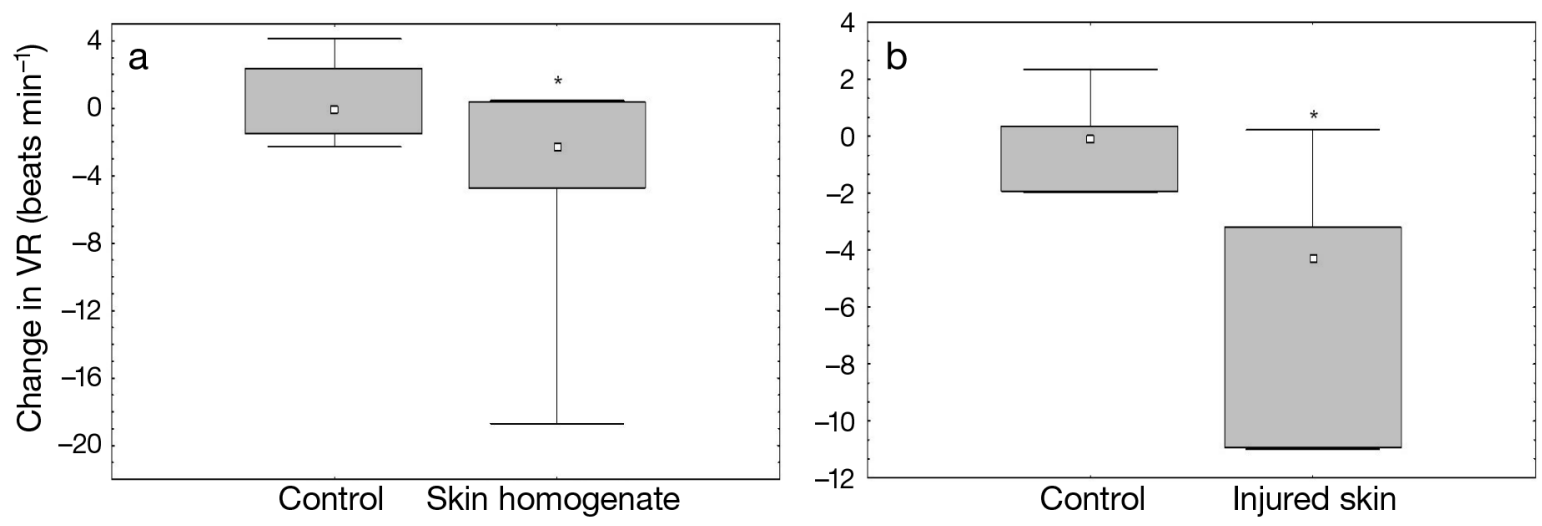

Fig. 1. Pseudoplatystoma coruscans. Changes in ventilatory rate (VR) in response to skin extract or distilled water (control). Data are shown as medians (small square), minimum and maximum obtained values (lines) and 25-75\% quartiles (boxes). Skin extract was obtained from (a) homogenised skin or (b) cut skin. * statistically significant difference to control (MannWhitney $U$-test; extract from homogenised skin, $\mathrm{p}=0.048, \mathrm{n}=7$; extract from cut skin, $\mathrm{p}=0.025, \mathrm{n}=6$ ). No significant difference in the magnitude of hypoventilation was found (Mann-Whitney $U$-Test, $p=0.32$ )

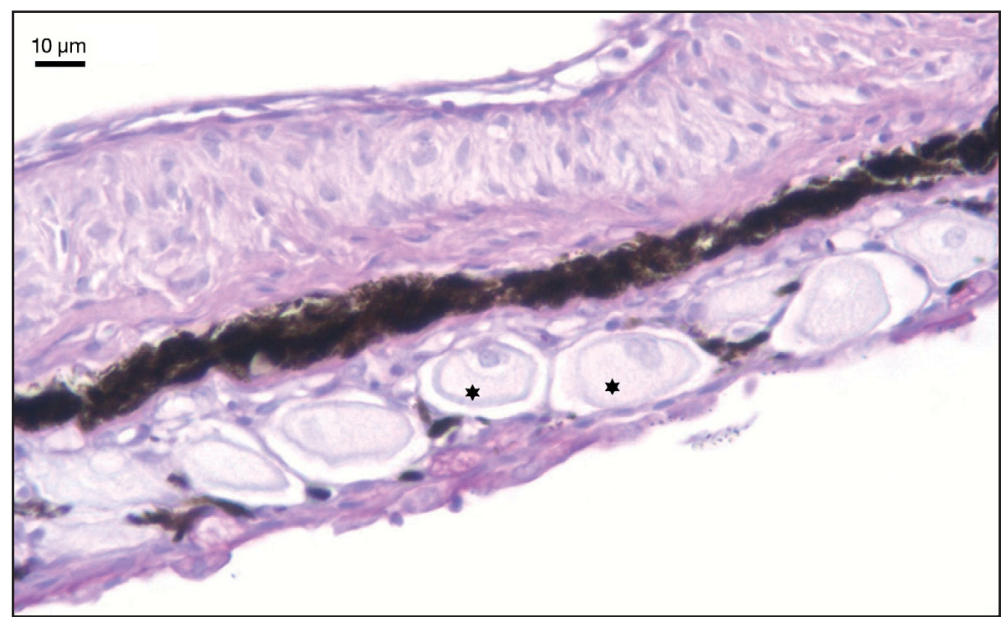

Fig. 2. Pseudoplatystoma coruscans. Micrograph from epidermis section showing club cells $(*)$
0.792, n $=6-5$ ) were not significant. No correlation between epidermis thickness and average score of club cells was found (feed-restricted donors, $\mathrm{p}=0.122$; full-fed donors, $\mathrm{p}=0.694$ ).

The catfish exposed to the skin extract from full-fed donors had lower VR values than those observed in fish exposed to the extract from feed-restricted donors or distilled water (Kruskal-Wallis test, $\mathrm{H}=$ 10.38, $p=0.006, n=7$ ) (Fig. 3). All of the tested fish stayed motionless throughout observation.

Expt 3: effect of extract concentration. The presence of the extract reduced the catfish VR when compared to the VR of the distilled water control group, but 


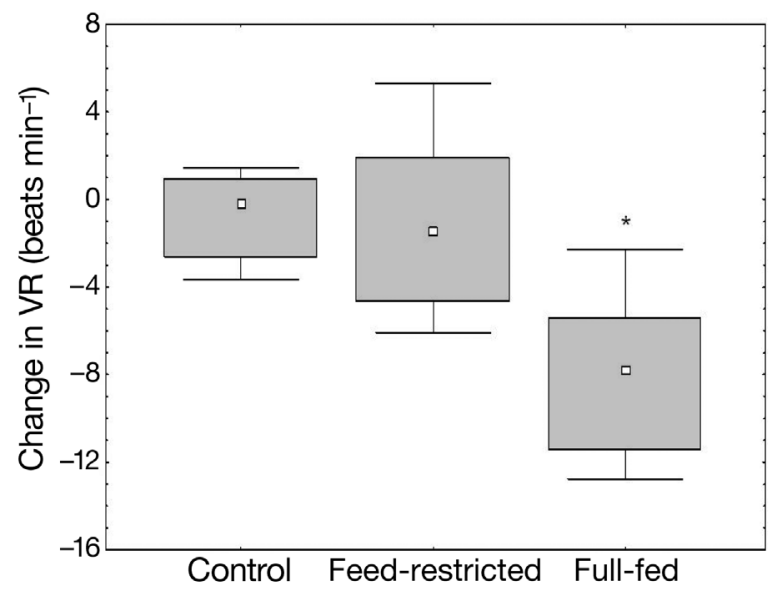

Fig. 3. Pseudoplatystoma coruscans. Changes in ventilatory rate (VR) in response to skin extract from feed-restricted or full-fed donors or to distilled water (control). Data are shown as medians (small square), minimum and maximum obtained values (lines) and $25-75 \%$ quartiles (boxes). ${ }^{*}$ significant difference (Kruskal-Wallis, $\mathrm{p}=0.006, \mathrm{n}=7$ )

there were no differences among the 3 tested extract volumes $(0.1,1.0$ and $15.0 \mathrm{ml})$. Significant betweengroup differences were found by performing a Kruskal-Wallis test $(\mathrm{H}=12.78, \mathrm{p}=0.005, \mathrm{n}=6$; Fig. 4). As observed in the prior trials, all of the tested fish of all conditions stayed motionless throughout experimentation.

\section{DISCUSSION}

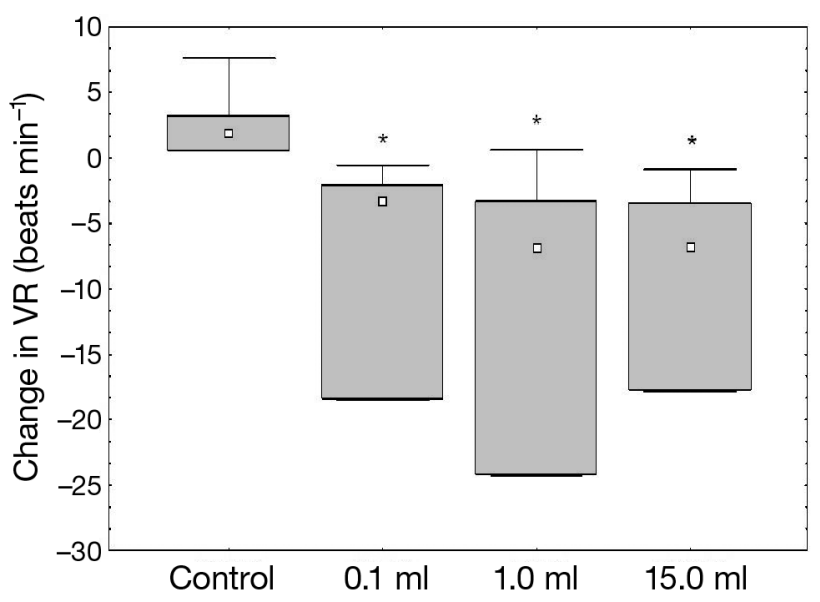

Fig. 4. Pseudoplatystoma coruscans. Changes in ventilatory rate (VR) in response to 3 different volumes of skin extract from full-fed fish or distilled water (control). Data are shown as median (small square), minimum and maximum obtained values (lines) and $25-75 \%$ quartiles (boxes). ${ }^{*}$ significantly different from control (Kruskal-Wallis, $\mathrm{p}=0.005, \mathrm{n}=6$ )
Investigations of different fish species have shown that a predator threat causes the VR to increase, independent of the sensory modality used to detect the imminent risk (von Frisch 1941, Metcalfe et al. 1987, Barreto et al. 2003, 2010, Hawkins et al. 2004a,b, 2007, Queiroz \& Magurran 2005, Gibson \& Mathis 2006). This VR response has also been observed for other stressors, such as social (Volpato et al. 1989, Alvarenga \& Volpato 1995, Barreto \& Volpato 2006), handling (Möck \& Peters 1990), strobe light (Sager et al. 2000), confinement (Barreto \& Volpato 2004, Brown et al. 2005, Bell et al. 2010), novelty (Barreto \& Volpato 2011) or cyanobacterial intoxication (Ernst et al. 2007). In our experiment, skin extracts caused hypoventilation in the speckled catfish. This hypoventilation occurred in the absence of escape behaviour, such as dashing, a reaction previously described in this species (Giaquinto \& Volpato 2001). Decreased activity can be linked to an increased VR, as reported for Nile tilapia (Barreto et al. 2010), suggesting preparedness for an escape task. However, based on our results, another possibility is that fish may avoid a predator not by fleeing but by staying motionless along with a decline in VR as a way to enhance crypsis and, consequently, become less susceptible to detection by predators (as the VR reduction might lead to decreased water vibration). In fact, numerous predators use prey movements to guide their first contact with the prey (Burrows et al. 1994, Burrows \& Gibson 1995).

To obtain a skin extract we used a classical method. This technique consisted of homogenising skin in distilled water and filtering the resulting liquid, which is provided as the chemical alarm cue (Brown et al. 2004, 2006, Foam et al. 2005). This skin extract induced hypoventilation in catfish, and these fish showed no locomotive reactions. The VR of animals exposed to extract from superficial cuts was similar in magnitude to those exposed to the extracts obtained from the homogenate of skin. This result indicates that the hypoventilation response was independent of the extraction technique and is likely due to the putative chemical alarm cue present in the catfish skin.

The experiments of the present study reported in the last paragraph have not considered the feeding status of skin donors. Moreover, the animals were randomly caught from a stock tank, failing to eliminate variations in fish feeding, such as cannibalism, a common trait in this species (Kossowski 1996, Giaquinto \& Volpato 2005). The quality of chemical alarm cues is influenced by body condition. The extracts from donors with a better body condition cause 
a significantly stronger antipredator response in fish (Brown et al. 2004). Thus, we attempted to control for the body condition of the donor fish. Under one condition, the fish were fed daily (full-fed), and under the other condition, the donors were fed every other day (feed-restricted) during a $20 \mathrm{~d}$ period. The latter is the same feeding schedule as that of stock tank fish from previous experiments and therefore should have prevented any additional unpredictable effect of feeding. At the end of $20 \mathrm{~d}$, the full-fed fish were heavier and longer than the feed-restricted fish, but body condition did not differ between the feeding conditions. It is not easy to explain the absence of a significant difference between the condition factors of full-fed and feed-restricted fish, especially because the full-fed fish were heavier and longer than the feed-restricted ones. Thus, we considered that full-fed and feed-restricted fish were in similar feeding states. The absence of differences might be, for instance, due to the formation of fat stores in full-fed catfish instead of somatic growth, although this was not measured.

Independent of the body condition, however, only the extract obtained from full-fed donors induced a ventilatory response: the VR was reduced, and no dashing response was observed, in contrast to the dashing and freezing observed in previous studies (Giaquinto \& Volpato 2001). These skin donor fish did not differ in terms of body condition, but they did differ in terms of food intake. Because the alarm substance is likely a by-product of protein metabolism (Brown et al. 2001, 2003, Parra et al. 2009), the observed differences in VR responses are plausibly a result of the food intake differences. Considering the food intake by the donor fish rather than their body condition, full-fed fish extract decreased the VR, whereas feed-restricted fish extract did not induce changes in the VR.

Stronger antipredator responses to alarm substances from donors with better body conditions have been observed in other fish species (Brown et al. 2004, Roh et al. 2004). These authors have hypothesised that donors with better body conditions could produce more alarm cue per $\mathrm{cm}^{2}$ of skin or produce a compound that is more easily recognised by conspecifics. This phenomenon was also observed for heterospecific fish responses. Predatory dottybacks Pseudochromis fuscus were more attracted to skin extracts of damselfish Pomacentrus amboinensis prey that were in good body condition than of those in poor body condition (Lonnstedt et al. 2012). Moreover, the quantity of epidermal club cells can be affected by feeding in some species (Wisenden \&
Smith 1997, 1998). In the present study, however, the number of club cells in the skin of full-fed skin donors was the same as that of feed-restricted fish. This result clearly refutes the hypothesised stimulus of feeding on the production of club cells in the speckled catfish epidermis and indicates that, with better feeding, a higher food intake (and not body condition) induces a more easily detectable chemical cue, regardless of the number of club cells. It suggests that the production of a chemical alarm cue is independent of club cells. Although we must have prudence in respect to this possibility, some recent evidence suggests this new paradigm of the antipredator behaviour mediated by alarm chemical cues in fish. In fathead minnow Pimephales promelas, adult fish respond to larval skin extracts that still have no visible club cells (Carreau-Green et al. 2008).

The last experiment of the present study tested whether hypoventilation intensity could be modulated by exposing fish to increasing volumes of the full-fed fish chemical cue. Even the typical antipredator behaviour (dashing) previously described could depend on the quantity of a 'full-fed' extract. In other words, if a dose-response effect is observed, higher food intake leads to a more recognisable chemical cue in ostariophysan fish. In fact, graded responses to chemical cues in fish have been described (Dupuch et al. 2004, Foam et al. 2005, Barbosa Júnior et al. 2010), although several studies did not confirm this dose-response relationship (Chivers et al. 2001, Brown et al. 2001, Mirza and Chivers 2003, Roh et al. 2004). In our study, 3 volumes of the full-fed fish extract were tested: $0.10 \mathrm{ml}$ (based on Ide et al. 2003), $1.0 \mathrm{ml}$ (Barreto et al. 2010, the present study) and $15.0 \mathrm{ml}$ (Brown et al. 2004). Ide et al. (2003) showed that $0.10 \mathrm{ml}$ of skin extract induced dashing and freezing in the matrinxã Brycon cephalus. Brown et al. (2004) showed that $15 \mathrm{ml}$ of different types (regarding diet and body condition) of chemical alarm cues decreases the moving time, tank area used, distance to another conspecifics and aggressive encounters in the convict cichlid Archocentrus nigrofasciatus. Barreto et al. (2010) showed that $1 \mathrm{ml}$ of skin extract decreases locomotion and aggressive interaction and increases the VR in Nile tilapia Oreochromis niloticus. When we tested different extract volumes $(0.1$, 1.0 and $15.0 \mathrm{ml}$ ), the resulting hypoventilations were similar in magnitude, indicating the lack of a graded VR response. These findings make the results of Expts $2 \& 3$ ambiguous with respect to the effect of different consumption of food on the VR response. The decreased VR observed in response 
to full-fed fish extract but not to feed-restricted fish suggested that different volumes of the full-fed extract would induce a graded VR response, but this effect did not happen.

An alternative hypothesis to explain this paradox is the presence of a threshold. If the chemical is detected above a threshold level, individuals respond in an 'all-or-nothing' manner (Brown et al. 2001, Mirza \& Chivers 2003, Marcus \& Brown 2003). This explanation fits with our findings for Expts 2 and 3. The feed-restricted fish extract may be below a necessary threshold and therefore induced no change in the VR, while the different volumes $(0.1,1.0$ and $15.0 \mathrm{ml})$ of the full-fed fish extract were above this threshold, successfully inducing the decreased VR but at the same magnitude. Alternatively, the lack of graded hypoventilation to an alarm chemical cue might be a consequence of a limited VR plasticity. The hypoventilatory response cannot accommodate an extensive degree of fluctuation because it could lead to an hypoxic state or a transitory ventilatory arrest in the case of a pronounced decrease of VR. Consequently, hypoventilation could induce damage to hypoxiasensitive tissue, such as the brain, heart and some glands (Randall et al. 1997). If hyperventilation had taken place, a graded response would have been more probable because hyperventilation allows for a higher range of variation. However, hyperventilation to other stressful stimuli in fish indicates that VR is a very sensitive tool with which to evaluate several aversive conditions, but it is also not able to reflect the intensity of the stimulus (Barreto \& Volpato 2004, $\mathrm{Xu}$ et al. 2006). In a same way, hypoventilation is a relevant fish response to indicate the presence of a chemical alarm cue, but its magnitude would be limited due to physiological needs.

We found no significant hypoventilation in response to the chemical alarm cue from starved fish in Expt 2 but did observe hypoventilation in Expt 1, which used donor fish that were fed in the same manner as starved fish. This finding suggests that the feeding history of skin extract donors had a large impact on alarm response, but dose did not. This hypothesis merits testing in additional future experiments.

Hypoventilation is also reported to occur in response to fear in a predator-prey confrontation in cuttlefish (King \& Adamo 2006), piauçu fish Leporinus macrocephalus (Barbosa Júnior et al. 2012) and in common sole Solea solea (Cannas et al. 2012). We assume that the ventilatory response is likely due to a specific response to an alarm cue rather than a general response to a new scent in the water, because other species distinguish between the alarm cue and non-alarm cues (Mirza \& Chivers 2000, 2001a,b, 2002, Morishita \& Barreto 2011). Moreover, the effect of donor diet treatment on the ventilatory responses is consistent with the interpretation of a specific response rather than a general response. Thus, taken together, the results strongly support the hypothesis that hypoventilation is a genuine antipredator response to an alarm cue in speckled catfish. The key variables that induce dashing and freezing (Giaquinto \& Volpato 2001) versus hypoventilation with no swimming activity (the present study) remain unknown and must be clarified in future studies. Circumstantially and surprisingly, no dashing catfish were observed in this study; therefore, hyperventilation linked to dashing should also be assessed in future investigations.

Acknowledgements. The authors thank the indispensable technical assistance of A. d. S. Fim Pereira. This study is part of R.E.B.'s post-doctoral research accomplished as part of a FMRP-USP post-doctoral program under supervision of A.H. and was financially supported by the Fundação de Amparo à Pesquisa do Estado de São Paulo (FAPESP) (Process: 2005/04771-5).

\section{LITERATURE CITED}

Alvarenga CMD, Volpato GL (1995) Agonistic profile and metabolism in alevins of the Nile tilapia. Physiol Behav $57: 75-80$

Barbosa Júnior A, Magalhães EJ, Hoffmann A, Ide LM (2010) Conspecific and heterospecific alarm substance induces behavioural responses in piau fish Leporinus piau. Acta Ethol 13:119-126

Barbosa Júnior A, Alves FL, Pereira ASF, Ide LM, Hoffmann A (2012) Behavioral characterization of the alarm reaction and anxiolytic-like effect of acute treatment with fluoxetine in piauçu fish. Physiol Behav 105:784-790

> Barreto RE, Volpato GL (2004) Caution for using ventilatory frequency as an indicator of stress in fish. Behav Processes 66:43-51

> Barreto RE, Volpato GL (2006) Ventilatory frequency of Nile tilapia subjected to different stressors. J Exp Anim Sci 43: 189-196

Barreto RE, Volpato GL (2011) Ventilation rates indicate stress-coping styles in Nile tilapia. J Biosci 36:851-855

> Barreto RE, Luchiari AC, Marcondes AL (2003) Ventilatory frequency indicates visual recognition of an allopatric predator in naïve Nile tilapia. Behav Processes 60: 235-239

Barreto RE, Barbosa A, Giassi ACC, Hoffmann A (2010) The 'club' cell and behavioural and physiological responses to chemical alarm cues in the Nile tilapia. Mar Freshw Behav Physiol 43:75-81

Bell AM, Henderson L, Huntingford FA (2010) Behavioral and respiratory responses to stressors in multiple populations of three-spined sticklebacks that differ in predation pressure. J Comp Physiol B 180:211-220

Brown GE (2003) Learning about danger: chemical alarm 
cues and local risk assessment in prey fishes. Fish Fish 4: 227-234

> Brown GE, Adrian JC, Patton T, Chivers DP (2001) Fathead minnows learn to recognize predator odour when exposed to concentrations of artificial alarm pheromone below their behavioural-response threshold. Can J Zool 79:2239-2245

> Brown GE, Adrian JC, Naderi NT, Harvey MC, Kelly JM (2003) Nitrogen oxides elicit antipredator responses in juvenile channel catfish, but not in convict cichlids or rainbow trout: conservation of the ostariophysan alarm pheromone. J Chem Ecol 29:1781-1796

Brown GE, Foam PE, Cowell HE, Fiore PG, Chivers DP (2004) Production of chemical alarm cues in convict cichlids: the effects of diet, body condition and ontogeny. Ann Zool Fenn 41:487-499

> Brown C, Gardner C, Braithwaite VA (2005) Differential stress responses in fish from areas of high- and low-predation pressure. J Comp Physiol B 175:305-312

$>$ Brown GE, Rive AC, Ferrari MCO, Chivers DP (2006) The dynamic nature of antipredator behavior: prey fish integrate threat-sensitive antipredator responses within background levels of predation risk. Behav Ecol Sociobiol 61:9-16

> Burrows MT, Gibson RN (1995) The effects of food, predation risk and endogenous rhythmicity on the behaviour of juvenile plaice, Pleuronectes platessa L. Anim Behav 50:41-52

Burrows MT, Gibson RN, Maclean A (1994) Effect of endogenous rhythms and light conditions on foraging and predator-avoidance in juvenile plaice. J Fish Biol 45(Suppl A):171-180

Cannas M, Domenici P, Lefrançois C (2012) The effect of hypoxia on ventilation frequency in startled common sole Solea solea. J Fish Biol 80:2636-2642

> Carreau-Green ND, Mirza RS, Martinez ML, Pyle GG (2008) The ontogeny of chemically mediated antipredator responses of fathead minnows Pimephales promelas. J Fish Biol 73:2390-2401

Chivers DP, Smith RJF (1998) Chemical alarm signalling in aquatic predator-prey systems: a review and prospectus. Ecoscience 5:338-352

> Chivers DP, Mirza RS, Bryer PJ, Kiesecker JM (2001) Threat-sensitive predator avoidance by slimy sculpins: understanding the role of visual versus chemical information. Can J Zool 79:867-873

> Dupuch A, Magnan P, Dill LM (2004) Sensitivity of northern redbelly dace, Phoxinus eos, to chemical alarm cues. Can J Zool 82:407-415

> Ernst B, Hoeger SJ, O'Brien E, Dietrich DR (2007) Physiological stress and pathology in European whitefish (Coregonus lavaretus) induced by subchronic exposure to environmentally relevant densities of Planktothrix rubescens. Aquat Toxicol 82:15-26

> Fernandes MN, Rantin FT (1994) Relationships between oxygen availability and metabolic cost of breathing in Nile tilapia (Oreochromis niloticus): aquacultural consequences. Aquaculture 127:339-346

Foam PE, Mirza RS, Chivers DP, Brown GE (2005) Juvenile convict cichlids (Archocentrus nigrofasciatus) allocate foraging and antipredator behaviour in response to temporal variation in predation risk. Behaviour 142:129-144

Froese R (2006) Cube law, condition factor and weightlength relationships: history, meta-analysis and recommendations. J Appl Ichthyol 22:241-253
Giaquinto PC, Hoffmann A (2010) Role of olfaction and vision cues in feeding behavior and alarm reaction in the catfish pintado, Pseudoplatystoma corruscans. J Ethol 28: 21-27

> Giaquinto PC, Volpato GL (2001) Hunger suppresses the onset and the freezing component of the antipredator response to conspecific skin extract in speckled catfish. Behaviour 138:1205-1214

> Giaquinto PC, Volpato GL (2005) Chemical cues related to conspecific size in speckled catfish, Pseudoplatystoma coruscans. Acta Ethol 8:65-69

> Gibson AK, Mathis A (2006) Opercular beat rate for rainbow darters Etheostoma caeruleam exposed to chemical stimuli from conspecific and heterospecific. J Fish Biol 69: 224-232

Hanlon RT, Forsythe JW, Joneschild DE (1999) Crypsis, conspicuousness, mimicry and polyphenism as antipredator defences of foraging on Indo-Pacific coral reefs, with a method of quantifying crypsis from video tapes. Biol J Linn Soc 66:1-22

Hawkins LA, Magurran AE, Armstrong JD (2004a) Predatorinduced hyperventilation in wild and hatchery Atlantic salmon fry. J Fish Biol 65(Suppl. A):88-100

Hawkins LA, Magurran AE, Armstrong JD (2004b) Innate predator recognition in newly-hatched Atlantic salmon. Behaviour 141:1249-1262

Hawkins LA, Magurran AE, Armstrong JD (2007) Innate abilities to distinguish between predator species and cue concentration in Atlantic salmon. Anim Behav 73: 1051-1057

Holopainen IJ, Aho J, Vornanen M, Huuskonen H (1997) Phenotypic plasticity and predator effects on morphology and physiology of crucian carp in nature and in the laboratory. J Fish Biol 50:781-798

Hughes GM, Shelton G (1962) Respiratory mechanisms and their nervous control in fish. In: Lowenstein OE (ed) Advances in comparative physiology and biochemistry, Vol 1. Academic Press, New York, NY, p 275-364

Ide LM, Hoffmann A (2002) Stressful and behavioural conditions that affect reversible cardiac arrest in the Nile tilapia, Oreochromis niloticus (Teleostei). Physiol Behav 75:119-126

> Ide LM, Urbinati EC, Hoffmann A (2003) The role of olfaction in the behavioural and physiological responses to conspecific skin extract in Brycon cephalus. J Fish Biol 63:332-343

Johnsson JI, Höjesjö J, Fleming IA (2001) Behavioural and heart rate responses to predation risk in wild and domesticated Atlantic salmon. Can J Fish Aquat Sci 58:788-794

Jordão LC, Volpato GL (2000) Chemical transfer of warning information in non-injured fish. Behaviour 137:681-690

King AJ, Adamo SA (2006) The ventilatory, cardiac and behavioural responses of resting cuttlefish (Sepia officinalis L.) to sudden visual stimuli. J Exp Biol 209: 1101-1111

Kossowski C (1996) Prospects for catfish culture (Siluroidei) in South America. Aquat Living Resource 9(Spec Issue): 189-195

Kristensen EA, Closs GP (2004) Anti-predator response of naïve and experienced common bully to chemical alarm cues. J Fish Biol 64:643-652

Lonnstedt OM, McCormick MI, Chivers DP (2012) Wellinformed foraging: damage-released chemical cues of injured prey signal quality and size to predators. Oecologia 168:651-658 
Losey GS (2003) Crypsis and communication functions of UV-visible coloration in two coral reef damselfish, Dascyllus aruanus and D. reticulatas. Anim Behav 66: 299-307

Marcus JP, Brown GE (2003) Response of pumpkinseed sunfish to conspecific chemical alarm cues: an interaction between ontogeny and stimulus concentration. Can J Zool 81:1671-1677

Metcalfe NB, Huntingford FA, Thorpe JE (1987) The influence of predation risk on the feeding motivation and foraging strategy of juvenile Atlantic salmon. Anim Behav 35:901-911

Millidine KJ, Metcalfe NB, Armstrong JD (2008) The use of ventilation frequency as an accurate indicator of metabolic rate in juvenile Atlantic salmon (Salmo salar). Can J Fish Aquat Sci 65:2081-2087

> Mirza RS, Chivers DP (2000) Predator-recognition training enhances survival of brook trout: evidence from laboratory and field enclosure studies. Can J Zool 78 : 2198-2208

Mirza RS, Chivers DP (2001a) Chemical alarm signals enhance survival of brook char (Salvelinus fontinalis) during encounters with chain pickerel (Esox niger). Ethology 107:989-1005

> Mirza RS, Chivers DP (2001b) Are chemical alarm signals conserved within salmonid fishes? J Chem Ecol 27: 1641-1655

Mirza RS, Chivers DP (2002) Brook char (Salvelinus fontinalis) can differentiate chemical alarm cues produced by different age/size classes of conspecifics. J Chem Ecol 28:555-564

Mirza RS, Chivers DP (2003) Response of juvenile rainbow trout to varying concentrations of chemical alarm cue: response thresholds and survival during encounters with predators. Can J Zool 81:88-95

Möck A, Peters G (1990) Lysozyme activity in rainbowtrout, Oncorhynchus mykiss (Walbaum), stressed by handling, transport and water-pollution. J Fish Biol 37: 873-885

> Morishita VR, Barreto RE (2011) Black sea urchins evaluate predation risk using chemical signals from a predator and injured con- and heterospecific prey. Mar Ecol Prog Ser 435:173-181

Parra KV, Adrian JC Jr, Gerlai R (2009) The synthetic substance hypoxanthine 3-N-oxide elicits alarm reactions in zebrafish (Danio rerio). Behav Brain Res 205:336-341

Pfeiffer W (1977) Distribution of fright reaction and alarm substance cells in fishes. Copeia 4:653-665

Queiroz H, Magurran AE (2005) Safety in numbers? Shoal-

Editorial responsibility: Victor Meyer-Rochow,

Bremen, Germany ing behaviour of the Amazonian red-bellied piranha. Biol Lett 1:155-157

Randall D, Warren B, French K (1997) Eckert animal physiology: mechanisms and adaptations. 4th edn. WH Freeman \& Comp, New York

Roh E, Mirza RS, Brown GE (2004) Quality or quantity? The role of donor condition in the production of chemical alarm cues in juvenile convict cichlids. Behaviour 141: 1235-1248

Sager DR, Hocutt CH, Stauffer JR (2000) Base and stressed ventilation rates for Leiostomus xanthurus Lacepede and Morone americana (Gmelin) exposed to strobe lights. J Appl Ichthyol 16:89-97

Smith RJF (1992) Alarm signals in fishes. Rev Fish Biol Fish 2:33-63

Smith RJF (1999) What good is smelly stuff in the skin? Cross function and cross taxa effects in fish alarm substances. In: Johnston RE, Müller-Schwarze D, Sorensen P (eds) Advances in chemical signals in vertebrates. Plenum Press, New York, NY, p 475-487

Valentincic T, Caprio J (1994) Consummatory feedingbehavior to amino-acids in intact and anosmic channel catfish Ictalurus punctatus. Physiol Behav 55:857-863

Volpato GL, Frioli PMA, Carrieri MP (1989) Heterogeneous growth in fishes: some new data in the Nile tilapia, Oreochromis niloticus, and a general view about the causal mechanisms. Bol Fisiol Anim Univ Sao Paulo 13:7-22

> von Frisch K (1941) Über einen Schreckstoff der Fischhaut und seine biologische Bedeutung. J Comp Physiol A 29: 46-145

- Wisenden BD (2000) Olfactory assessment of predation risk in the aquatic environment. Philos Trans R Soc Lond B 355:1205-1208

Wisenden BD, Smith RJF (1997) The effect of physical condition and shoalmate familiarity on proliferation of alarm substance cells in the epidermis of fathead minnows. J Fish Biol 50:799-808

> Wisenden BD, Smith RJF (1998) A re-evaluation of the effect of shoalmate familiarity on the proliferation of alarm substance cells in ostariophysan fishes. J Fish Biol 53: 841-846

Wisenden BD, Karst J, Miller J, Miller S, Fuselier L (2008) Anti-predator behaviour in response to conspecific chemical alarm cues in an Esociform fish, Umbra limi (Kirtland 1840). Environ Biol Fishes 82:85-92

> Xu JY, Liu Y, Cui SR, Miao XW (2006) Behavioral responses of tilapia (Oreochromis niloticus) to acute fluctuations in dissolved oxygen levels as monitored by computer vision. Aquacult Eng 35:207-217

Submitted: September 7, 2011; Accepted: March 13, 2012 Proofs received from author(s): May 16, 2012 